\title{
Anti-CD39 Monoclonal Antibody TTX-030
}

National Cancer Institute

\section{Source}

National Cancer Institute. Anti-CD39 Monoclonal Antibody TTX-030. NCI Thesaurus.

Code C162693.

A fully human monoclonal antibody directed against the cell surface receptor CD39

(cluster of differentiation 39; ectonucleoside triphosphate diphosphohydrolase-1;

NTPDase1; ENTPD1) with potential immunomodulating and antineoplastic activities.

Upon administration, anti-CD39 monoclonal antibody TTX-030 specifically binds to the

CD39 antigen, which may inhibit both the conversion of adenosine triphosphate (ATP) to adenosine monophosphate (AMP) and the subsequent generation of

immunosuppressive extracellular adenosine in the tumor microenvironment (TME).

CD39, a cell surface ectonucleosidase, is upregulated on tumor cells as an immune evasion strategy; blocking its action may promote the stimulation of dendritic and other myeloid-derived cells that are necessary for both innate and adaptive immunity. 